\title{
PENGARUH KADAR FLY ASH TERHADAP KUAT TEKAN PADA HIGH VOLUME FLY ASH SELF COMPACTING CONCRETE (HVFA-SCC) BENDA UJI SILINDER D 7,5 CM X 15 CM USIA 14, 28 DAN 90 HARI
}

\author{
Rinzano Genta Satria'), Wibowo ${ }^{2)}$, Endah Safitri ${ }^{3)}$ \\ 1) Mahasiswa Program Studi Teknik Sipil, Fakultas Teknik, Universitas Sebelas Maret Surakarta \\ 2) 3) Pengajar Program Studi Teknik Sipil, Fakultas Teknik, Universitas Sebelas Maret Surakarta \\ Jalan Ir. Sutami 36A, Surakarta, 57126; Tlp 0271-647069, Email: rinzanogenta@gmail.com
}

\begin{abstract}
The advancement of time and technology influences the development of concrete technology, such as development of concrete with the capability of self compacting. Addition of high volume fly ash and BASF-8851 superplasticizer material can make concrete denser, have a high compressive strength value and have good working ability. This study uses variations of fly ash concentration by $0 \%, 55 \%, 60 \%, 65 \%$ and $70 \%$ of the weight of cement. This study is divided into two types, namely testing of fresh concrete and dry concrete. Fresh concrete testing has three types of testing, including flow table test, $l$-box test and $v$-funnel test. Dry concrete testing is done by doing compressive strength test through Universal Testing Machine (UTM). The test object is made in cylindrical shape measuring $7.5 \mathrm{~cm}$ in diameter with a height of $15 \mathrm{~cm}$. Based on the results of the study, it was found that only the $70 \%$ fly ash concentration met all SCC concrete testing requirements. Optimum concrete compressive strength was found at 90 days at $65.08 \%$ fly ash concentration. Furthermore, it has been obtained a level of fly ash that meets the parameters of high quality concrete and self-soliding concrete (SCC) at the test age of 14 days, 28 days and 90 days, namely at $70 \%$ fly ash concentration.
\end{abstract}

Keywords: self-compacting concrete, high strength concrete, high volume fly ash, $7.5 \mathrm{~cm} \times 15 \mathrm{~cm}$ cylindrical specimen.

\begin{abstract}
Abstrak
Perkembangan zaman dan teknologi mempengaruhi perkembangan teknologi beton menjadi lebih pesat seperti membuat beton berkemampuan memadat mandiri. Penambahan fly ash dalam jumlah besar (high volume fly ash) dan penambahan bahan superplasticizer BASF-8851 mampu membuat beton lebih padat, memiliki nilai kuat tekan yang tinggi dan memiliki kemampuan kerja yang baik. Pengujian kali ini menggunakan variasi kadar fly ash sebesar 0\%, $55 \%, 60 \%, 65 \%$ dan $70 \%$ dari berat semen. Jenis pengujian dibagi menjadi dua jenis, yaitu pengujian beton segar dan beton kering. Pengujian beton segar memiliki tiga jenis pengujian, antara lain flow table test, l-box test dan $v$-funnel test. Pengujian beton kering dilakukan dengan melakukan uji kuat tekan melalui alat Universal Testing Machine (UTM). Benda uji dibuat dalam bentuk silinder berukuran diameter 7,5 $\mathrm{cm}$ dengan tinggi $15 \mathrm{~cm}$. Berdasarkan hasil penilitian didapat bahwa hanya kadar fly ash $70 \%$ yang memenuhi seluruh persyaratan pengujian beton SCC. Berikutnya terdapat nilai kuat tekan beton optimum terhadap variasi kadar fly ash terdapat pada umur 90 hari pada kadar fly ash 65,08\%. Selanjutnya telah didapat suatu kadar fly ash yang memenuhi parameter beton mutu tinggi dan beton memadat mandiri (SCC) pada umur uji 14 hari, 28 hari dan 90 hari yaitu pada kadar fly ash $70 \%$.
\end{abstract}

Kata Kunci : beton memadat mandiri, beton mutu tinggi, high volume fly ash, benda uji d 7,5 cm x $15 \mathrm{~cm}$.

\section{PENDAHULUAN}

Perkembangan zaman mempengaruhi perkembangan teknologi beton yang semakin pesat, salah satunya dengan menambahkan suatu zat kimia atau zat pozzolanic ke dalam campuran beton. Hal ini dilakukan dengan tujuan untuk meningkatkan nilai kuat tekan beton serta untuk mencapai beton Self Compacting Concrete (SCC).

Beton mutu tinggi dapat didefinisikan sebagai beton yang memiliki nilai kuat tekan lebih tinggi dari nilai kuat tekan beton normal biasa. Menurut SNI 03-6468-2000, yang disebut beton mutu tinggi adalah beton yang memiliki kuat tekan yang disyaratkan lebih besar sama dengan 41,4 MPa. 
Dalam penelitian kali ini penguji menambahkan fly ash dan superplasticizer ke dalam campuran beton. Penambahan kadar fly ash yang digunakan dalam jumlah besar, yaitu diatas $50 \%$ dari berat semen, penambahan kadar fly ash dalam jumlah besar ini biasa disebut dengan High Volume Fly Ash (HVFA).

Penambahan HVFA pada campuran beton memiliki keunggulan pada saat beton segar maupun saat beton keras. Beberapa keunggulannya pada saat beton segar adalah kehalusan dari partikel fly ash yang bulat akan mengisi ruang terkecil pada campuran sehingga akan meningkatkan nilai workability dan mampu mengurangi kelecakan. Pada saat beton keras maka keunggulannya dapat dilihat dari sisi kuat tekan akan meningkat cukup signifikan setelah usia beton diatas 56 hari, meningkatkan durabilitas beton dan mengurangi penyusutan beton (Nugraha, Antoni, 2007).

Keunggulan penggunaan superplasticizer dalam campuran beton antara lain dapat menjaga kandungan air dan semen tetap konstan sehingga didapatkan campuran dengan workability tinggi, menghasilkan faktor air semen yang lebih rendah dan mampu meminimalisir udara yang masuk ke dalam beton.

Berdasarkan hasil penelitian Shabina Aulia (2017) yang menggunakan benda uji berbentuk silinder dengan diameter $15 \mathrm{~cm}$ dan tinggi $30 \mathrm{~cm}$, penambahan kadar fly ash sebesar 70\% merupakan kadar terbaik yang memenuhi semua persyaratan pengujian beton segar, yaitu memenuhi semua sifat dari beton SCC. Sementara itu, kuat tekan maksimum terdapat pada beton dengan kadar fly ash sebesar $60 \%$, yaitu 22,82 MPa untuk beton umur 14 hari dan 29,43 MPa untuk beton umur 28 hari.

\section{METODE}

\section{Benda Uji}

Pada penilitian kali ini, benda uji yang digunakan berbentuk silinder dengan ukuran diameter 7,5 cm dan tinggi $15 \mathrm{~cm}$.

\section{Rancang Campur (Mix Design)}

Kadar bahan beton yang digunakan pada tiap $1 \mathrm{~m}^{3}$ dapat dilihat pada Tabel 1. di bawah ini

Tabel 1. Rancang Campur Bscc - FA per $1 \mathrm{~m}^{3}$

\begin{tabular}{|c|c|c|c|c|c|c|}
\hline Kode. & $\begin{array}{l}\text { Ag. Kasar } \\
\left(\mathrm{Kg} / \mathrm{m}^{3}\right)\end{array}$ & $\begin{array}{c}\text { Ag. Halus } \\
\left(\mathrm{Kg} / \mathrm{m}^{3}\right)\end{array}$ & $\begin{array}{l}\text { Semen } \\
\left(\mathrm{Kg} / \mathrm{m}^{3}\right)\end{array}$ & $\begin{array}{r}\text { Fly Ash } \\
\left(\mathrm{Kg} / \mathrm{m}^{3}\right)\end{array}$ & $\underset{\left(1 t / \mathrm{m}^{3}\right)}{\operatorname{Air}}$ & $\begin{array}{l}\text { Superplasticizer } \\
\qquad\left(1 \mathrm{t} / \mathrm{m}^{3}\right)\end{array}$ \\
\hline $\begin{array}{l}\text { Bscc-FA } \\
0 \%\end{array}$ & 801,25 & 916,32 & 550 & 0 & 165 & 4,13 \\
\hline $\begin{array}{l}\text { Bscc-FA } \\
55 \%\end{array}$ & 801,25 & 885.45 & 247.50 & 302.5 & 165 & 4,13 \\
\hline $\begin{array}{l}\text { Bscc-FA } \\
60 \%\end{array}$ & 801,25 & 882.64 & 220 & 330 & 165 & 4,13 \\
\hline $\begin{array}{l}\text { Bscc-FA } \\
65 \%\end{array}$ & 801,25 & 879.83 & 192.5 & 357.5 & 165 & 4,13 \\
\hline $\begin{array}{l}\text { Bscc-FA } \\
70 \%\end{array}$ & 801,25 & 877.03 & 165 & 385 & 165 & 4,13 \\
\hline
\end{tabular}

\section{Pengujian Beton Segar}

Pengujian beton SCC ini dilakukan sesuai dengan standar EFNARC (2002) yaitu Slump Flow Test, L-Box Test dan $V$-Funnel Test. Tinjauan utama dari pengujian ini adalah terhadap parameter beton SCC yaitu passingability, fillingability dan segregation resistance.

\section{Pengujian Beton Keras}

Pengujian beton keras dilakukan dalam bentuk pengujian kuat tekan beton dengan menggunakan alat Universal Testing Machine (UTM) dengan umur uji 14 hari, 28 hari dan 90 hari. 


\section{HASIL DAN PEMBAHASAN}

\section{Hasil Pengujian Beton Segar}

Berikut ini merupakan hasil pengujian beton segar yang dapat dilihat dalam Tabel 2.

Tabel 2. Hasil Pengujian Beton Segar

\begin{tabular}{|c|c|c|c|c|c|c|c|c|c|c|c|c|}
\hline \multicolumn{5}{|c|}{ Flow Table Test } & \multicolumn{4}{|c|}{ L-Box Test } & \multicolumn{4}{|c|}{$V$-Funnel Test } \\
\hline Kode & $\begin{array}{l}d_{\text {rerata }} \\
(\mathrm{mm})\end{array}$ & $\begin{array}{c}\text { Syarat } \\
(\mathrm{mm})\end{array}$ & $\begin{array}{c}\mathrm{T}_{500} \\
(\mathrm{~s})\end{array}$ & $\begin{array}{c}\text { Syarat } \\
\text { (s) }\end{array}$ & $\mathrm{h}_{2} / \mathrm{h}_{1}$ & $\begin{array}{l}\text { Syarat } \\
\mathrm{h}_{2} / \mathrm{h}_{1}\end{array}$ & $\begin{array}{c}\mathrm{T}_{200} \\
(\mathrm{~s})\end{array}$ & $\begin{array}{c}\mathrm{T}_{400} \\
(\mathrm{~s})\end{array}$ & $\begin{array}{c}\text { Waktu } \\
\text { Aliran } \\
\text { Awal / } \\
\mathrm{T}_{\text {awal }} \\
(\mathrm{s})\end{array}$ & $\begin{array}{c}\text { Syarat } \\
\mathrm{T}_{\text {awal }} \\
\text { (s) }\end{array}$ & $\begin{array}{c}\text { Waktu } \\
\text { Aliran } 5 \\
\text { menit } \\
/ \\
\text { T5min } \\
\text { (s) }\end{array}$ & $\begin{array}{c}\text { Syarat } \\
\mathrm{T}_{5 \mathrm{~min}} \\
(\mathrm{~s})\end{array}$ \\
\hline $\begin{array}{c}\text { Bscc } \\
-\mathrm{FA} \\
0 \%\end{array}$ & 665 & $\begin{array}{c}650 \\
- \\
800\end{array}$ & 3,1 & $2-5$ & 1,00 & $\begin{array}{c}0,8 \\
- \\
1,0\end{array}$ & 1,0 & 2,7 & 8,3 & $8-12$ & 12,2 & +3 \\
\hline $\begin{array}{c}\text { Bscc } \\
-\mathrm{FA} \\
55 \%\end{array}$ & 755 & $\begin{array}{c}650 \\
- \\
800\end{array}$ & 4,4 & $2-5$ & 0,67 & $\begin{array}{c}0,8 \\
- \\
1,0\end{array}$ & 2,15 & 4,4 & 20,5 & $8-12$ & 44 & +3 \\
\hline $\begin{array}{r}\text { Bscc } \\
-\mathrm{FA} \\
60 \%\end{array}$ & 745 & $\begin{array}{c}650 \\
- \\
800\end{array}$ & 4,2 & $2-5$ & 0,80 & $\begin{array}{c}0,8 \\
- \\
1,0\end{array}$ & 2,25 & 4,2 & 14,5 & $8-12$ & 21 & +3 \\
\hline $\begin{array}{c}\text { Bscc } \\
- \text { FA } \\
65 \%\end{array}$ & 730 & $\begin{array}{c}650 \\
- \\
800\end{array}$ & 2,7 & $2-5$ & 0,80 & $\begin{array}{c}0,8 \\
- \\
1,0\end{array}$ & 1,4 & 2,7 & 11 & $8-12$ & 17 & +3 \\
\hline $\begin{array}{c}\text { Bscc } \\
-\mathrm{FA} \\
70 \%\end{array}$ & 710 & $\begin{array}{c}650 \\
- \\
800\end{array}$ & 2,0 & $2-5$ & 0,90 & $\begin{array}{c}0,8 \\
- \\
1,0\end{array}$ & 1,2 & 2,0 & 8,5 & $8-12$ & 10 & +3 \\
\hline
\end{tabular}

\section{Hasil Flow Table Test}

Berikut ini merupakan grafik hasil pengujian flow table yang dapat dilihat pada Gambar 1 dan Gambar 2.

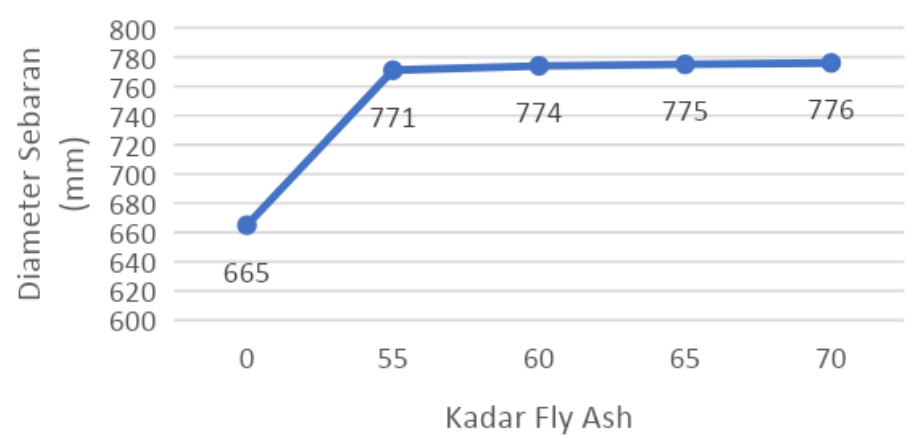

(\%)

Gambar 1. Grafik Diameter Sebaran Flow Table Test dengan Kadar Fly Ash 


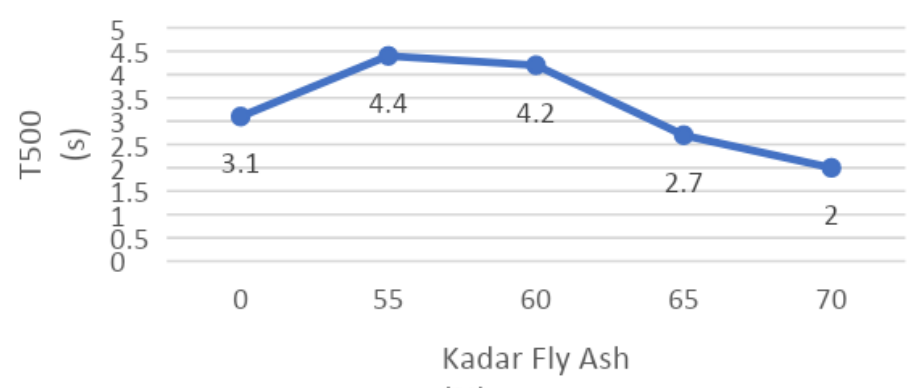

(\%)

Gambar 2. Grafik $T_{500}$ pada Flow Table Test dengan Kadar Fly Ash

Berdasarkan Gambar 1 sampai dengan Gambar 2 yang menunjukkan pengaruh kadar fly ash terhadap diameter sebaran dan waktu $t_{500}$ beton, semakin tinggi kadar fly ash yang dicampurkan maka diameter sebaran dan waktu $\mathrm{t}_{500}$ akan semakin meningkat pula. Beton dengan variasi kadar fly ash $70 \%$ memiliki diameter sebaran tertinggi sebesar $776 \mathrm{~mm}$ dengan waktu t500 sebesar 2,0 detik.

Hal ini sesuai dengan pernyataan Malhotra dan Mehta (2005), bahwa menurut pertimbangan referensi dan beberapa pengalaman percobaan, penggunaan fly ash dengan kadar lebih dari $50 \%$ berat total binder selain dapat meningkatkan kekuatan maksimum dan ketahanan, juga dapat meningkatkan workability dari beton tersebut.

\section{Hasil L-Box Test}

\section{L-Box Test Results}

Berikut ini merupakan grafik hasil pengujian L-Box yang dapat dilihat pada Gambar 3 dan Gambar 4.

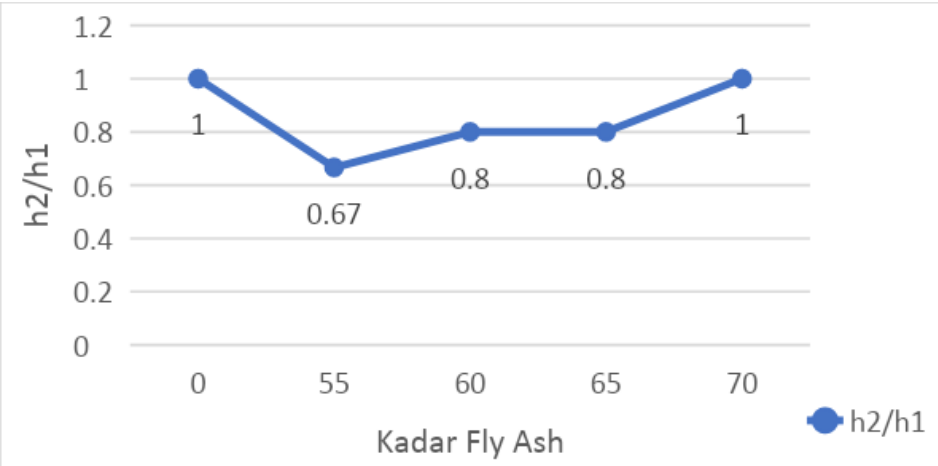

Gambar 3. Grafik $\mathrm{h}_{2} / \mathrm{h}_{1}$ pada L-Box Test dengan Kadar Fly Ash

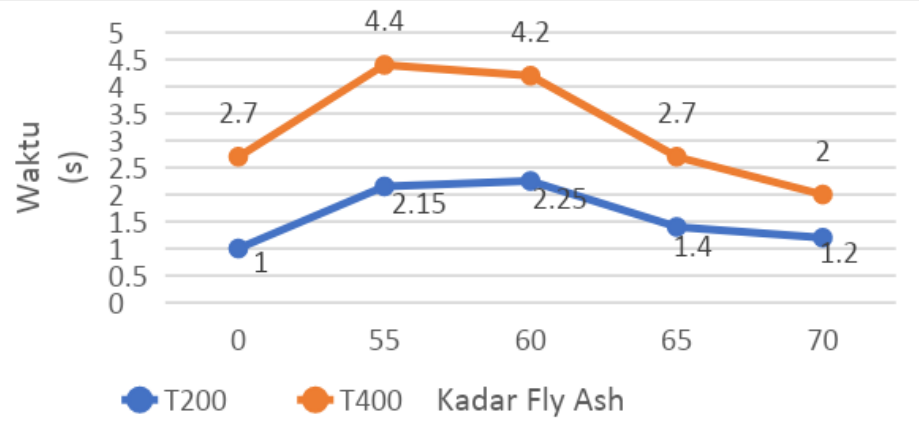

(\%)

Gambar 4. Grafik $\mathrm{T}_{200}$ dan $\mathrm{T}_{400}$ pada L-Box Test dengan Kadar Fy Ash 
Pada Gambar 3 dapat dilihat bahwa kadar fly ash 55\% tidak memenuhi syarat EFNARC 2002, karena nilai $\mathrm{h}_{2} / \mathrm{h}_{1}$ berada di bawah 0,8 . Sedangkan variasi kadar fly ash $60 \%$ dan fly ash $65 \%$ mengalami penurunan nilai $\mathrm{h}_{2} / \mathrm{h}_{1}$ dari beton kadar fly ash $0 \%$. Hal ini disebabkan oleh viskositas beton yang cukup tinggi karena adanya gumpalan antara semen dan fly ash yang masih didominasi oleh semen, akan tetapi pada kadar fly ash $70 \%$ kembali pada nilai optimum.

Sedangkan dari Gambar 4 menunjukkan hubungan antara $\mathrm{t}_{200} \mathrm{~mm}$ dan $\mathrm{t}_{400 \mathrm{~mm}}$ dengan masing-masing kadar fly ash, bahwa kenaikan waktu pengaliran dari beton dengan kadar fly ash $0 \%$ (non-filler) ke beton dengan kadar fly ash 55\%, 60\%, 65\% dan 70\% (ber-filler), kemungkinan disebabkan oleh proses pengadukan antara beton nonfiller dan beton ber-filler dilakukan pada hari yang berbeda. Hal itulah yang memungkinkan adanya perbedaan kondisi temperatur, keadaan alat uji.

\section{Hasil V-Funnel Test}

Berikut ini merupakan grafik hasil pengujian V-Funnel yang dapat dilihat pada Gambar 5.

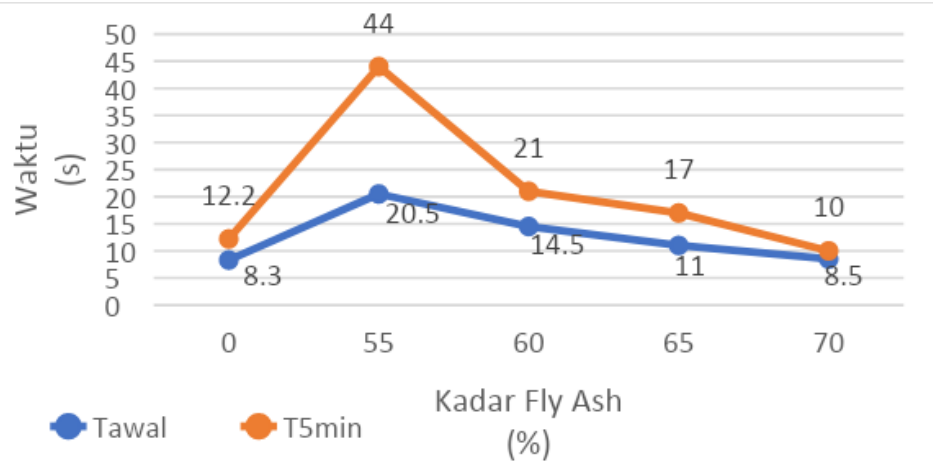

Gambar 5. Grafik Waktu Aliran pada V-funnel Test dengan Kadar Fly Ash

Berdasarkan Gambar 5 dapat dilihat bahwa hanya kadar fly ash 0\% dan fly ash 70\% saja yang memenuhi persayaratan $\mathrm{T}_{\text {awal }}$ dan $\mathrm{T}_{5 \min }$. Kadar fly ash 55\%, 60\% dan 65\% yang tidak memenuhi syarat terindikasi telah terjadi segregasi.

Hasil pengujian kuat tekan beton tercantum pada Tabel 3 dan Gambar 6 berikut ini.

Tabel 3. Hasil Uji Kuat Tekan Umur 14 Hari, 28 Hari dan 90 Hari.

\begin{tabular}{|c|c|c|c|}
\hline Kode & $\begin{array}{c}\text { Kuat Tekan } \\
\text { 14 Hari (MPa) }\end{array}$ & $\begin{array}{c}\text { Kuat Tekan } \\
\text { 28 Hari (MPa) }\end{array}$ & $\begin{array}{c}\text { Kuat Tekan } \\
\mathbf{9 0} \text { Hari (MPa) }\end{array}$ \\
\hline Bscc- FA 0\% & 36,58 & 43,02 & 45,07 \\
\hline Bscc- FA 55\% & 16,20 & 22,74 & 50,32 \\
\hline Bscc- FA 60\% & 17,13 & 23.77 & 52,26 \\
\hline Bscc- FA 65\% & 16,01 & 24,70 & 55,75 \\
\hline Bscc- FA 70\% & 14,11 & 20.11 & 53,15 \\
\hline
\end{tabular}

Berdasarkan Tabel 3 di atas, nilai kuat tekan beton filler baru mengalami kenaikan pada saat umur uji 90 hari. Hal ini disebabkan karena durasi yang diperlukan zat kimia $\mathrm{Ca}(\mathrm{OH})_{2}$ dengan zat silika $\mathrm{SiO}_{2}$ yang terkandung di 
dalam fly ash untuk bereaksi cukup lama, sehingga produk CSH sebagai penguat beton akan semakin lama pula terbentuk.

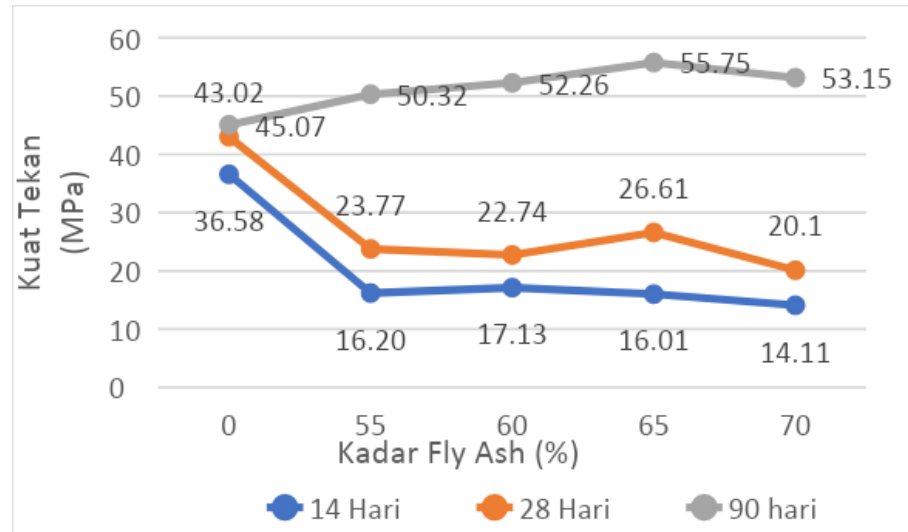

Gambar 6. Grafik Kuat Tekan Beton D 7,5 cm x 15 cm dengan Kadar Fly Ash

Berdasarkan Gambar 6 dapat dilihat bahwa semakin bertambahnya umur beton yang diuji, maka akan nilai kuat tekannya akan semakin tinggi pula. Nilai kuat tekan maksimum pada setiap variasi umur uji beton 14 hari berada pada variasi fly ash 60\%. Sedangkan, pada umur uji beton 28 hari dan 90 hari berada pada variasi fly ash 65\%. Hal ini terjadi karena pada variasi kadar fly ash $70 \%$, beton sudah mencapai titik jenuh sehingga fly ash yang ditambahkan justru akan menyerap banyak air dan menyebabkan campuran beton sukar melekat. Hal ini sesuai dengan penelitian Purba (2015) bahwa nilai kuat tekan beton variasi fly ash 70\% merupakan yang paling kecil dibandingkan nilai kuat tekan beton variasi fly ash 50\% dan fly ash 60\% pada umur beton uji 28 hari.

Nilai kuat tekan optimum beton terhadap variasi kadar fly ash beton d 7,5 cm x $15 \mathrm{~cm}$ dapat diketahui melalui Gambar 7 di bawah ini

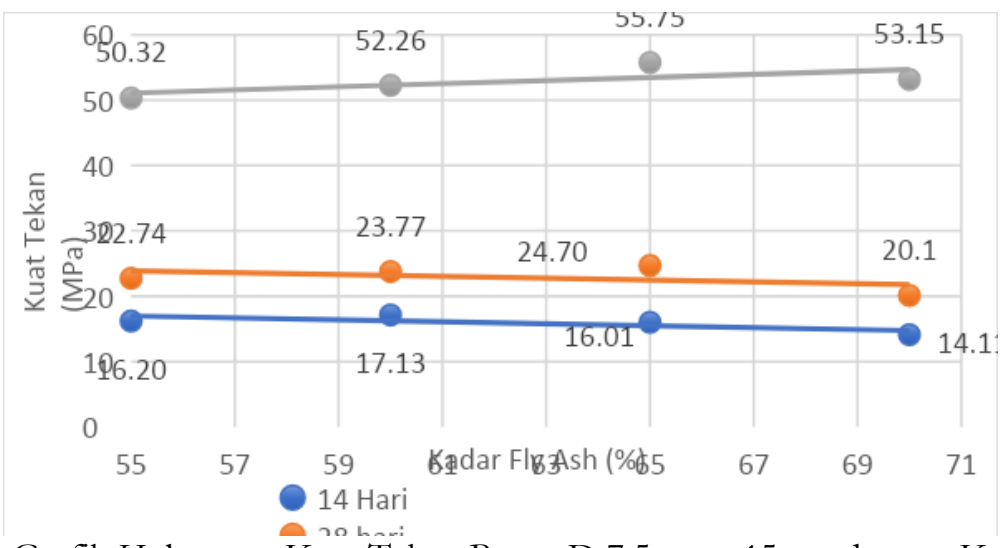

Gambar 7. Grafik Hubungan Kuat Tekan Beton D 7,5 cm x $15 \mathrm{~cm}$ dengan Kadar Fly Ash

Berdasarkan Gambar 7 didapat persamaan kuadratik untuk kuat tekan beton pada umur 14 hari, 28 hari dan 90 hari. Berdasarkan pada persamaan kuadratik ini nantinya akan diperoleh persentasi kadar fly ash yang menghasilkan kuat tekan optimum pada beton silinder dengan d 7,5 cm x $15 \mathrm{~cm}$ umur pengujian 14, 28 dan 90 hari. Namun, disebabkan nilai kuat tekan mutu tinggi hanya tercapai pada usia uji 90 hari, maka hanya pada kadar 90 hari saja yang diambil nilai kuat tekan optimumnya. Adapun kuat tekan 90 hari, persamaan kuadratiknya adalah $\mathrm{y}=-0.0455 \mathrm{x}^{2}+5.9224 \mathrm{x}-138.28$ sehingga nilai kuat tekan optimum berada pada kadar fly ash sebesar $65,08 \%$. 


\section{KESIMPULAN}

Berdasarkan hasil pengujian dan analisis yang dilakukan secara eksperimen mengenai pengaruh kadar fly ash terhadap kuat tekan pada High Strength Self Compacting Concrete (HSSCC) benda uji silinder d 7,5 cm x $15 \mathrm{~cm}$ usia 14 dan 28 hari, dapat diambil kesimpulan sebagai berikut:

a) Berdasarkan hasil pengujian SCC pada beton segar, kadar yang mampu memenuhi seluruh parameter SCC (fillingability, passingability dan segregation resistance) hanya pada penggantian semen dengan kadar fly ash 70\% saja.

b) Dengan adanya penambahan fly ash pada High Strength Self Compacting Concrete (HSSCC) pada beton silinder d 7,5 cm x $15 \mathrm{~cm}$ terjadi penurunan nilai kuat tekan terhadap nilai kuat tekan beton non-filler pada umur uji 14 hari dan 28 hari, kemudian mengalami kenaikan nilai kuat tekan terhadap beton non-filler pada umur uji 90 hari.

c) Nilai kuat tekan beton terhadap umur pengujian masih cenderung meningkat, sehingga didapat nilai kuat tekan maksimum pada kadar fly ash 65\% di umur uji 90 hari. Sedangkan, nilai kuat tekan optimum beton terhadap variasi kadar fly ash pada umur 90 hari terjadi pada kadar fly ash sebesar 65,08\%.

d) Persentase kadar fly ash yang digunakan untuk memenuhi parameter beton mutu tinggi dan beton memadat mandiri pada beton silinder dengan d 7,5 cm x $15 \mathrm{~cm}$ umur pengujian 14 hari, 28 hari dan 90 hari adalah sebesar $70 \%$

\section{REFERENSI}

Badan Standarisasi Nasional. 2000. Tata Cara Perencanaan Campuran Beton Berkekuatan Tinggi dengan Semen Portland dan Abu Terbang (SNI 03-6468-2000). Jakarta Pusat: Badan Standarisasi Nasional.

EFNARC. 2002. Specification and Guidelines for Self-Compacting Concrete.

Malhotra, V.M. and Mehta, P.K. 2005. High-Performance, High-Volume Fly Ash Concrete for Sustainable Development. University of California, USA.

Nugraha, P dan Antoni. 2007. Teknologi Beton. Yogyakarta: Andi Offset.

Utami, SA. 2017. "Kajian Pengaruh Variasi Komposisi High Volume Fly Ash 